\title{
Road Network Planning for Sustainable Urban Development in Kirtipur Municipality, Nepal
}

\author{
Bikash Kumar Karna \\ Survey Officer, Survey Department, Min Bhawan, Kathmandu, Nepal.
}

\begin{abstract}
Road network deals with the development of a comprehensive plan for construction and operation of transportation facilities. In order to develop efficient and better transport facility, it is necessary to have a proper road network. In sustainable road network planning, planners put into consideration factors like gradients or slope, land-use and geology with community and governmental interest. These different considerations make the planning process complex and generate confusion in the decision making process. The use of geographic information system (GIS) and multi-criteria analysis (MCA) has helped planners to reduce complexity and to achieve desired and more accurate results. MCA prevents the imposition of criteria limit and gives opportunity to decision makers to enter their own judgments. This provides a better communication among the decision makers and the entire community for creating a more open choice for analysis and possible changes if necessary. In this study, road network has been analyzed with optimal least cost path algorithm of spatial analysis in GIS using different ancillary data layers and each layer weight-scoring has been computed with $M C A$ in spatial decision support system (SDSS). The optimal least cost path would provide the best option with certainty and considers a gradient, connected neighbors, thematic cost and surface distance in three dimensional spaces. The path gradient can be adjusted as per the requirements, depending upon the terrain conditions and possible to design a more realistic route automatically with appropriate parameters.
\end{abstract}

Keywords

Road planning, multi-criteria analysis, spatial decision support system, optimal least cost path.

\section{Introduction}

Road planning deals with definition of circulation infrastructure pavements, roads and terminals. It al so covers the physical and operational characteristics of public transport (Vasconcellos, 2001). Effective road path is an essential interest of every developing country and acts as a means of interconnectivity between different parts and regions within and outside the country. Road network provides the country's economic and social well-being for the mobility of people and goods, but also over the long term it influences patterns of growth, land use and economic activities. But, road network development has damage and fragments the natural environment. Human- kind's quest for development has led to a point where any further development threatens the last remaining natural reserves. So, finding the optimal balance between infrastructure creation and nature conservation is achieving greater importance for sustainable development (World B ank, 2010).

Road network needs to the identifying and reserving of land for urban transport facilities that support connectivity between different location of urban place. Road network planning plays an undeniably key role in the economic growth of any region/ country. So, the planning can be done heedlessly and detrimental to the biophysical and social environment of the region. In road route planning generally one or a few alternative routes are proposed for environmental impact assessment (EIA) and strategic environmental assessment (SEA) using SDSS. An efficient road route planning system that directly takes into account the environmental, social and economical considerations in formulating, assessing and selecting alternative routes are proposed for sustainable infrastructure development (K eshkamat et al., 2009). 
During the last decade, RS and GIS technology have been used for route-planning process. Costs are increased by long structures, by large volumes of cut and fill, and by unbalanced cut and fill. For designing the high quality road, needs suitable spatial data such as geology, land use, slope, soil and drainage. GIS coupled with MCA has hel ped to enhance multicriteria decision making associated with planning process (Roy, 1996; M aha, 2012). The use of GIS with MCA has helped for decision makers towards actualizing the optimal route for desired choice and enhance in decision making process (Chakhar \& M artel, 2003; Geneletti, 2004).

\section{Study Area \& Data used:}

Study A rea Kirtipur municipality has high rate of urban growth and urban sprawl has prevalent with the rapid development of urbanization and motorization. There is need of a comprehensive road netw ork planning for the establishment systematic of dreamland city. The location of study area is shown in Figurel.

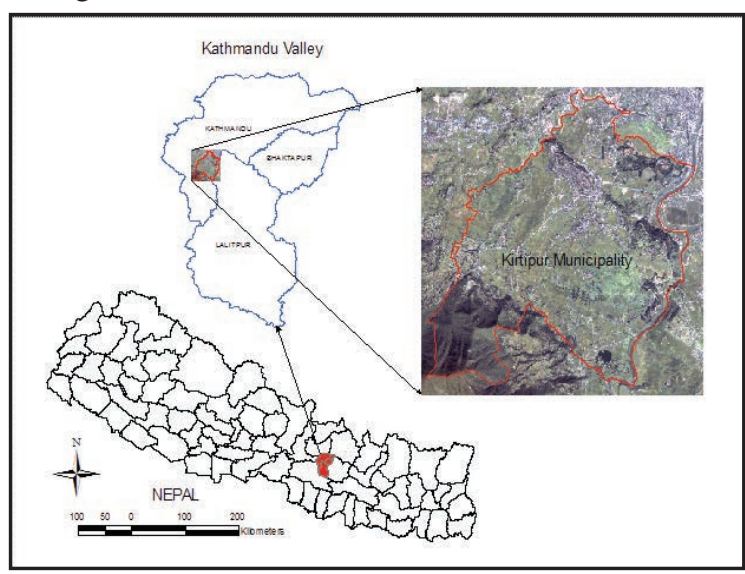

Figure1: Study Area

Its location is $27038^{\prime} 37^{\prime \prime}$ to $277^{\circ} 41^{\prime} 36^{\prime \prime} \mathrm{N}$ and $85^{\circ} 14^{\prime} 64^{\prime \prime}$ to 850 18' 00" $\mathrm{E}$ with it extent and at present has 19 wards and covers $17.87 \mathrm{sq} . \mathrm{km}$. It is bordered by the Bagmati River with Lalitpur Submetropolitian City to the east, Machhengaun Village Development Committee (VDC) to the west, $\mathrm{K}$ athmandu metropolitan city (KMC) to the north, and Chalnakhel VDC to the south. The town was built initially within a wall surrounded strategically by dense vegetation and opens ground as outer rings. Data used The following datasets were used in the study; these are listed bel ow in Table 1.
Table1:

Description of Data used

\begin{tabular}{|l|l|l|l|}
\hline Data Type & Year & $\begin{array}{l}\text { Scale } \\
\text { Resolution }\end{array}$ & Source \\
\hline Remotely Sensed Data: \\
\hline GeoEye -1 & 2012 & $2 \mathrm{~m}$ & UB M P \\
\hline Base M ap: & 1996 & $1: 25000$ & DOS \\
\hline Topo map & 1998 & $1: 2000$ & DOHUD \\
\hline U rban map & 2007 & $1: 30000$ & NLUP \\
\hline A ncillary Vector Layers/D ata: \\
\hline \begin{tabular}{l} 
Geology \\
\hline Field Data:
\end{tabular} & $\begin{array}{l}\text { F i e I d } \\
\text { Works }\end{array}$ \\
\hline $\begin{array}{l}\text { Ground Control } \\
\text { Point (GCP) }\end{array}$ & 2012 & $\begin{array}{l}\text { F i e I d } \\
\text { Works }\end{array}$ \\
\hline Ground Truth & 2012 &
\end{tabular}

\section{R oad Alignment}

Road alignment is the location of the centre line of the road in the ground. It has included two components; one is the horizontal alignment which is the straight connected path with its horizontal deviation and horizontal curves and other is the vertical alignment which is the change in gradient defined by ruling gradient and the vertical curves of the road. It is chosen carefully based on the consideration of the road construction cost with its maintenance and road improvement, operation of vehicle cost and accident rate with its requirement and different factors (K hanna \& J usto, 1971).

Road Alignment Requirements: The basic requirements of ideal al ignment betw een two terminal stations are short, easy, safe and economical.

Road Alignment Factors: The various factors are considered while selecting the road alignment. In general, obligatory points, traffic flow, geometric design, slope stability, drainage, resisting length, economic condition are considered as factors in road network planning (K hanna \& Justo, 1971).

\section{M ethodology}

The procedure helps to select a least cost route that is supposed to be the best and reducing overall road development and maintenance costs. The proposed route planning procedure can be divided into the following four basic steps: 
4.1 Thematic Cost Raster: A scoring system in the range of 0 to 9 is used, with zero signifying the minimum cost and 9 implying the highest cost. Similarly, the influence factor of each layer is w eighting with between 0 to 1 values so that the whole influence of the thematic cost raster is 1 or $100 \%$. The weighting-scoring (rating) values are based on a comparative study of various thematic data layers and discussions with experts working in the area of transportation engineering. M ulti Criteria Evaluation is used for the thematic cost raster generation and is computed as (Saha et al., 2005):

Thematic Cost Value $=\Sigma$ Weight $*$ Score

4.2 Selection of Connected Neighbors: Neighbourhood is the location within proximity of some starting-point or grid cell. In a $3 \times 3$ pixel window, there are eight direct neighbors (two horizontal, two vertical and four diagonal). The turn angle interval (angle between an incoming and outgoing path at a pixel) for the route is restricted to a minimum 450 angle. In GIS, a raster based model based on the neighborhood relationship concept are used to each pixel can be represented as a network node. This step involves finding various possibilities of the connected nodes in terms of horizontal and vertical factor respectively in terms of moving direction with the horizontal relative moving angle (HRMA) and the moving from one cell to another cell in vertical direction with the vertical relative moving angle (VRM A) to slope or gradient.

\subsection{Calculation of Neighborhood M ovement C ost} (NM-cost): Once connected neighbors are found, the cost of moving to the connected neighbor from a source is called as neighborhood movement cost (N M -cost and calculated as (Saha et al., 2005) :

NM Cost $=$ Surface Distance $*$ Thematic Cost Raster

However, if the topography is uneven, the slope of the terrain varies in different ranges with different directions. Therefore, the NM-cost must consider this direction dependency (anisotropy), for which, the N M -cost may be given as:

N M Cost $=$ Surface Distance $*$ Thematic Cost

$$
\text { Raster * Slope Cost }
$$

4.4 Selection of least-cost route: For directhorizontal/ vertical connection involves finding least cost shortest path using path distance and is calculated as (Saha et al., 2005):

Path distance $=$ Surface $D$ istance $*$

Thematic Cost Raster $* \frac{\sum \beta_{\mathrm{i}} \times \mathrm{p}}{\mathrm{n}} * \mathrm{q} ; \mathrm{i}=1, \ldots, 4 \quad 4$

where $p \& q$ are the horizontal and vertical factor for each cell respectively and $n$ is the total number of cell. Similarly, for the diagonal direct connection, i.e. the Bishop's pattern, the neighbour-distance is calculated as:

Path distance $=$ Surface D istance $*$

Thematic Cost Raster $* \sqrt{2} * \frac{\sum \beta_{\mathrm{i}} \times \mathrm{p}}{\mathrm{n}} * \mathrm{q} ; \mathrm{i}=5, \ldots, 8 \quad 5$

where $p \& q$ are the horizontal and vertical factor for each cell respectively and $n$ is the total number of cell. A ccumulation path distance is the accumulation cost to from cell to the end cell and given by

$$
\text { A ccumulation Cost }=\Sigma \mathrm{a}_{\mathrm{i}}
$$

where is the path distance of the link from one cell to the adjacent another cell.

\section{Result \& Analysis}

Triangulated irregular network (TIN) surface was generated using contour data in $2 \mathrm{~m}$ contour interval from urban base map TIN surface was smoothed for the purpose of engineering quality contours using linear interpolation and converted into DEM with TIN to Raster tool in A rcGIS 10 (in Figure 2).

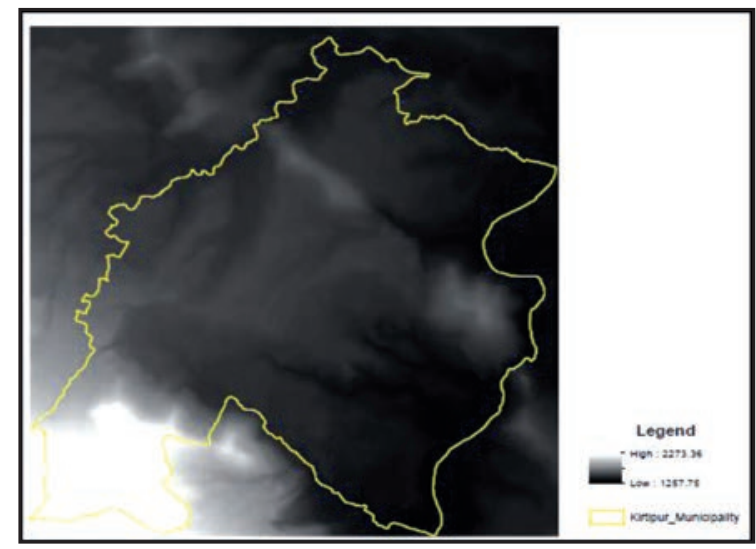

F igure 2: DEM of the Study Area

L and use land cover (LULC) map for the year 2012 were prepared by maximum likelihood classifier (M LC) technique of multi-spectral Geoeye-1 images. 
LULC map was categorized into five classes such as built-up, agriculture, forest, water body and open space. The validation of classification results were done for the quantification and evaluation of error using confusion matrix which compares the class-byclass based on the training samples and classification result classes. These error matrices were evaluated and the overall accuracy has found $87.67 \%$ with $\mathrm{K} \mathrm{IA}$ 0.8337. The LULC map is shown in Figure 3.

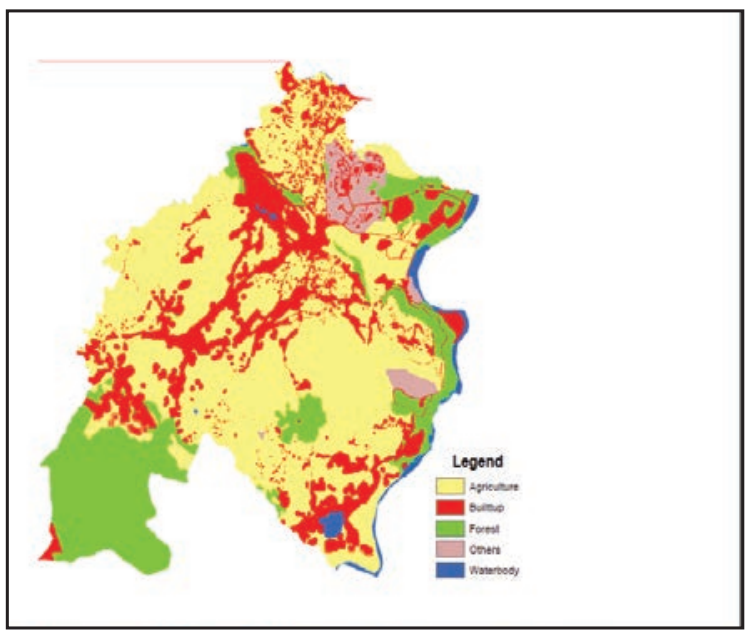

Figure 3: Land use land cover

The thematic road network was generated from ortho-rectified Geoeye-1 image. The road network was categorized into four classes as highway, feeder road, major road and minor road. In road raster; some pixels have the raster value of highway, feeder road, major road and minor road but not cover all pixels by these road types having discrete type of geographic phenomenon. So, this discrete geographic phenomenon was converted into continuous phenomenon by reclassification of $\mathrm{No}$ data of road raster into one category as No Road. The continuous raster of road network map is shown in Figure 4.

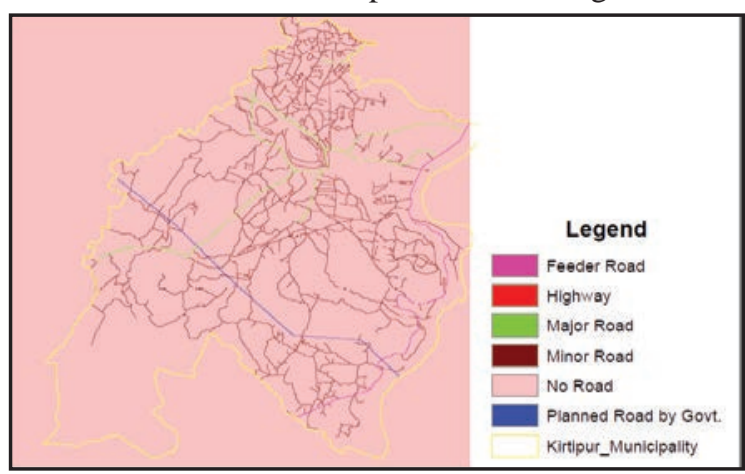

Figure 4: Reclassified Road Network
The thematic drainage network was also generated from ortho-rectified Geoeye-1 image. The drainage network was categorized into four classes as river/ lake, khola, major stream and stream. In raster drainage; some pixels has the raster value of river/ lake, khola, major stream and stream but not cover all pixel by these drainage type having discrete type of geographic phenomenon. So, this discrete geographic phenomenon was converted into continuous phenomenon by reclassification of $\mathrm{No}$ data of drainage system raster into one category as No Stream. The continuous drainage system map is presented in Figure 5.

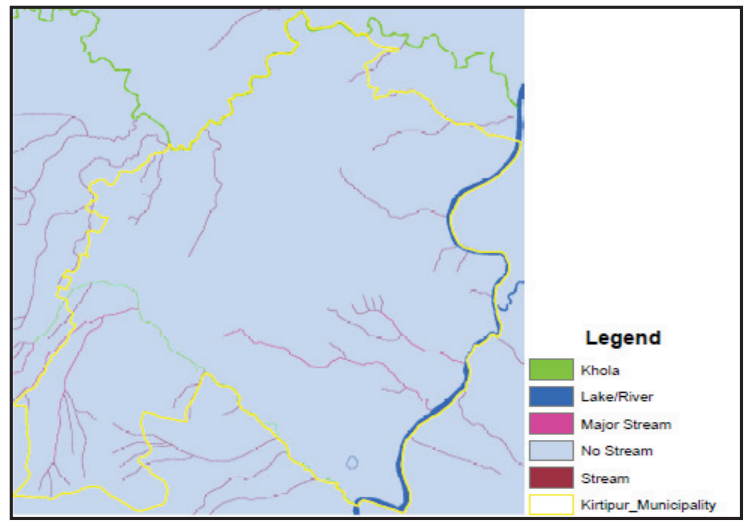

Figure 5: Reclassified Drainage Network

The thematic distance to settlement layer was generated from the existing settlement from the LULC map and verified from Geoeye-1 image using Euclidian distance in spatial analysis tool and found distance ranges from $0 \mathrm{~m}$ to $1732 \mathrm{~m}$. These ranges of distance to settlement was categorized into six categories from $0 \mathrm{~m}$ to $100 \mathrm{~m}, 100 \mathrm{~m}$ to $300 \mathrm{~m}, 300 \mathrm{~m}$ to $500 \mathrm{~m}, 500 \mathrm{~m}$ to $1 \mathrm{~km}, 1 \mathrm{~km}$ to $1.5 \mathrm{~km}$ and $1.5 \mathrm{~km}$ to above. The result of reclassification of distance to settlement map is shown in Figure 6.

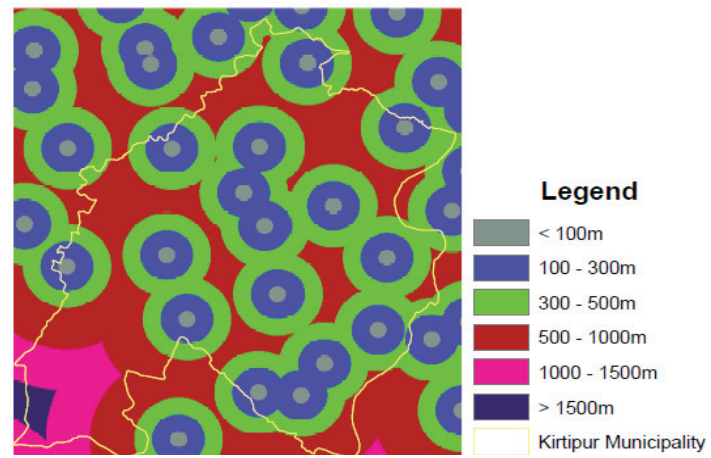

Figure 6: Reclassified Distance to Settlement 
The slope was derived from the DEM and its ranges from 00 to 720 . This range of slope was categorized into five categories such as from $0 \%$ to $5 \%, 5 \%$ to $10 \%, 10 \%$ to $15 \%, 15 \%$ to $20 \%$ and $20 \%$ to above. The result of reclassification of slope map is presented in Figure 7.

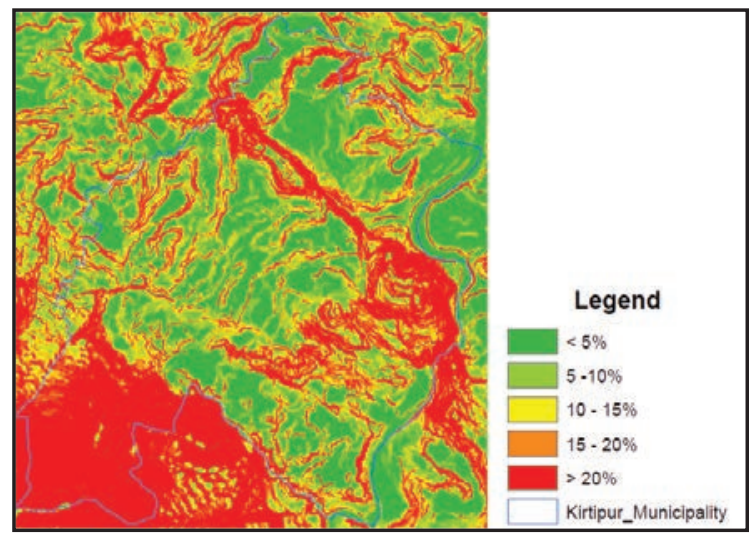

Figure 7: Classified Slope M ap

The thematic cost raster surface was generated with the weighted overlay of different raster having different score (attribute rating) and weight (factor/ criteria rating) consultation with expert using $\mathrm{MCE}$ technique in customize tool with model builder and python. Slope is the most important parameter in road planning in a mountainous terrain for maintaining the ruling gradient of road al ignment. Slope is categorized into five sub-categories and individual sub-categories have rating with its score value in the ordinal number from 0 to 9 . Road construction and maintenance in the steep slope is high cost comparative to the flat terrain. The score of different slope categories are shown in Table 2.

Table 2: Score of Slope Category

\begin{tabular}{|c|c|}
\hline Slope & Score \\
\hline$<5 \%$ & 2 \\
$5-10 \%$ & 5 \\
$10-15 \%$ & 7 \\
$15-20 \%$ & 8 \\
$>20 \%$ & 9 \\
\hline
\end{tabular}

LULC data has required for estimating the cost of land acquisition during road route planning. The areas covered with river sediments are also not suitable for road construction, as these are susceptible to flood inundation. The score of different LULC categories are shown in Table 3.
Table 3: Score of LULC Category

\begin{tabular}{|c|c|}
\hline LULC & Score \\
\hline A griculture & 6 \\
Built-up & 8 \\
Forest & 4 \\
Open Space & 2 \\
Waterbody & 9 \\
\hline
\end{tabular}

Lithology mainly concerned with structure of rock type which has been considered mainly for the costs of blasting, excavation, cut-and-fill works, etc. The score of different lithology categories are shown in Table 4.

Table 4: Score of Lithology Category

\begin{tabular}{|c|c|}
\hline Lithology Category & Score \\
\hline Quartizite & 9 \\
Slate & 7 \\
Limestone & 5 \\
L acustine & 3 \\
Alluvial Fan & 1 \\
\hline
\end{tabular}

The road network is mainly defines its order by the road type. The road type map has been used here to consider the reduction in the cost of construction so that planned route followed the existing route of road. Generally, where the existing metallic road such as highway and feeder road exist, there is no need for more excavation work for base and sub-base only upgrading is required. The score of different road categories are shown in Table 5.

Table 5: Score of Road Class

\begin{tabular}{|c|c|}
\hline Road Class & Score \\
\hline Highway & 1 \\
Feeder Road & 3 \\
M ajor Road & 5 \\
M inor Road & 7 \\
No Road & 9 \\
\hline
\end{tabular}

The drainage system is categorized by the order of the stream. The drainage-order map has been used to consider the cost of a possible bridge construction. Generally, the width of the river channel increases with increasing order of drainage, which results in a corresponding increase in the cost of bridge construction. The first- and second-order drainages (streams) have been assigned very low ratings where as higher-order drainages (river/khola) has assigned the high value. The pixels without any channel have 
been assigned a low cost. The score of different drainage type are shown in Table 6.

Table 6: Score of Drainage Type

\begin{tabular}{|c|c|}
\hline Drainage Type & Score \\
\hline River & 9 \\
K hola & 7 \\
M ajor Stream & 5 \\
M inor Stream & 3 \\
No Stream & 1 \\
\hline
\end{tabular}

For the accessibility to people, distance to settlement is an important factor in the road planning. M ain road inside the settlement is not good for the vision of safety to avoid accident. The score of distance from settlement are shown in Table 7.

Table 7: Score of Distance to Settlement

\begin{tabular}{|c|c|}
\hline Distance to Settlement & Score \\
\hline$<100 \mathrm{~m}$ & 9 \\
$100-300 \mathrm{~m}$ & 2 \\
$300-500 \mathrm{~m}$ & 5 \\
$500-1000 \mathrm{~m}$ & 7 \\
$1000-1500 \mathrm{~m}$ & 8 \\
$>1500 \mathrm{~m}$ & 9 \\
\hline
\end{tabular}

The proposed road alignment alternatives were generated based on slope, LULC, lithology, road netw ork, stream system and distance settlement. The first alternative weight was assigned from expert knowledge and validated from A nalytic hierarchy process (A HP) pair wise comparison. In all pair wise comparison test we get overall consistency having limit less than 0.1. The w eight obtained from the A HP pair wise comparison for the al ternative 1 , al ternative 2 and al ternative 3 are shown in Table 8.

Table 8: Weight of different A Iternatives

\begin{tabular}{|l|l|l|l|}
\hline \multirow{2}{*}{\multicolumn{1}{c|}{ Factors }} & \multicolumn{3}{c|}{ Weight } \\
\cline { 2 - 4 } & Alter-1 & Alter-2 & A lter-3 \\
\hline Slope & 0.25 & 0.22 & 0.23 \\
\hline LULC & 0.20 & 0.19 & 0.19 \\
\hline Lithology & 0.15 & 0.15 & 0.15 \\
\hline Road Network & 0.15 & 0.17 & 0.19 \\
\hline Drainage Network & 0.15 & 0.14 & 0.11 \\
\hline $\begin{array}{l}\text { Distance to } \\
\text { Settlement }\end{array}$ & 0.15 & 0.12 & 0.13 \\
\hline
\end{tabular}

Path distance and path direction i.e. back link of the surface cost path computes the total cost surface from the source location to each and every pixel. The result of path distance and path direction were computed from source (K irtipur Centre Nayabazar) using path distance spatial analysis tool (in Figure 8).

Figure 8: Path Distance and Direction from Source

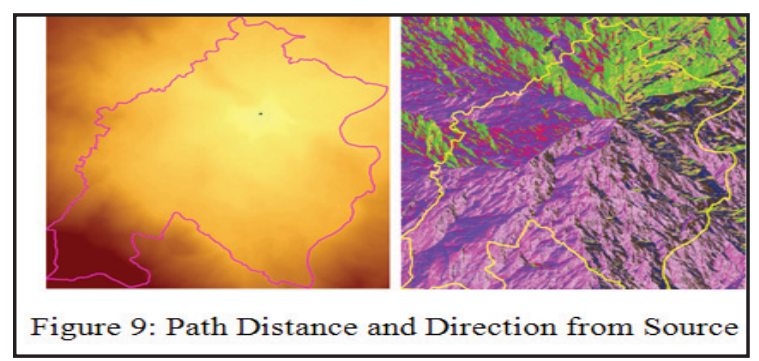

Least cost path route was computed from the optimized path distance and its back link raster (path direction) to the different destination location using least cost path al gorithm (cost path) in spatial analysis tool in A rcGIS 10. The proposed road network in 2030 obtained using least cost path for major road from Nayabazar K irtipur as source (existing urban centre) to different destination location which will be future urbanized. The proposed three alternative road networks from different weight for thematic cost surface and then least cost path were determined (in Figure 9).

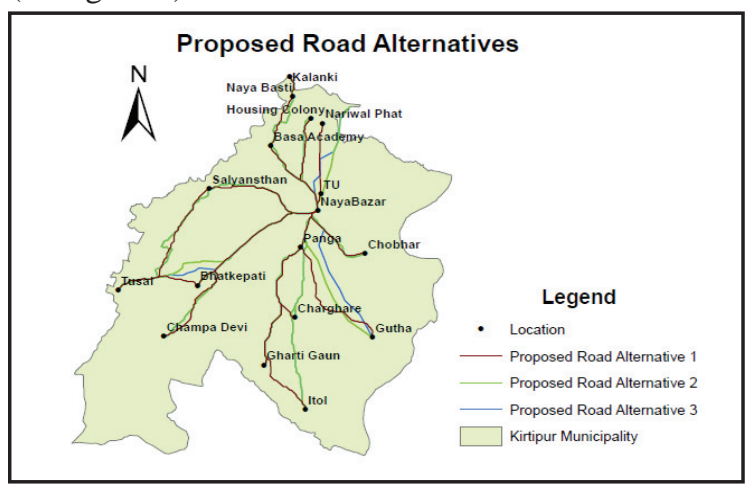

Figure 9: Road Network Alternatives

The multi-criteria analysis was carried out using weighted summation method and interval standardization for ranking of alternatives in D efinite Software. Sensitivity analysis was also conducted to analyze the sensitivity of ranking through assessment of the score and the weight uncertainty in defining the priority of alternatives. Relative importance for each effect showed that the road length is most important compared to others effects. The result of multi-criteria is shown in Figure 10. The uncertainty in length and gradient used are $0.10 \%$ and $0.15 \%$ 
respectively. Road network alternative 1,2 and 3 have total accumulation value $0.75,0.50$ and 0.67 respectively. The results indicate that proposed road network alternative 1 is better compared to proposed road network alternatives 2 and 3 .

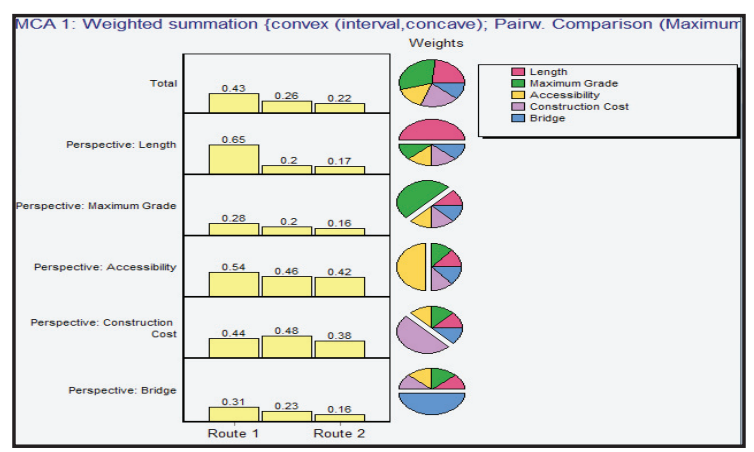

Figure 10: Multi-criteria Analysis

From multi-criteria analysis and sensitivity analysis the proposed road network alternative 1 is the best for construction having less length and suitable maximum gradient. The road length and suitable gradient of proposed road network alternative 1 is minimum ranking level, so this al ternative is sel ected for purposed road network in future 2030.

\section{Conclusion}

The planning of road has become a complex task with the consideration of different criteria's/factors associated with its weight-scoring. The analysis for sustainable road network planning has achieved with the ground parameters, expert knowledge and model in A RCGIS or customized with python. In spatial analysis assessment, the intermediate and final results from the model has based on its pre-assumption of criteria consideration and related with its weight-

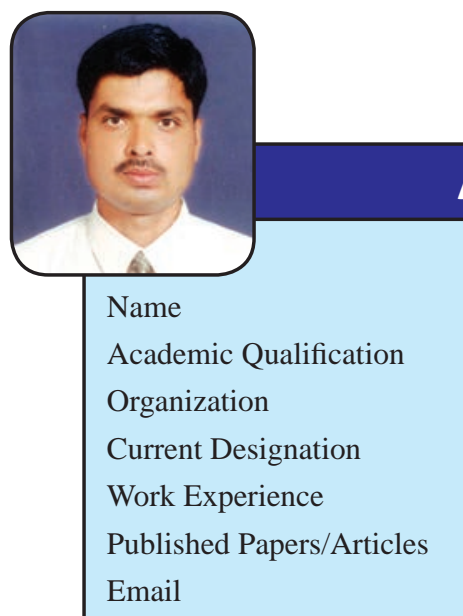

\section{Author's Information}

Mr. Bikash Kumar Karna

P.G. Diploma in Remote Sensing \& GIS

Survey Department

Survey Officer

14 Year

One

bikashkumarkarna@gmail.com 